\title{
Fresh-cut Fruits in Thailand
}

\author{
Nithiya Rattanapanone, Chansuda Chongsawat, and Soungsuda Chaiteep \\ Department of Food Science and Technology, Faculty of Agro-Industry, Chiang Mai University, \\ Chiang Mai, 50200, Thailand
}

Fresh-cut fruits have been marketed in Thailand for many years, and sales of fresh-cut products have been increasing in both openair markets as well as in supermarkets. Freshcut fruits are popular in Thailand because of the inconvenience of preparation of some fruits for consumption and limited refrigerated space in homes. Fruits such as jackfruit (Artocarpus heterophyllus Lam.), pineapple [Ananas comosus (L.) Murr.], and durian (Durio zibethinus L.) are difficult to peel. Some fruits such as jackfruit, watermelon (Citrullus lanatus L.), and papaya (Carica papaya L.) are quite large and cannot be consumed at one sitting by most families. Durian emits a sulfurous odor, which can be offensive when the fruit is kept overnight in a room or house. Jackfruit is large ( 5 to $>20 \mathrm{~kg}$ ) and is very difficult to cut because of a gummy latex that exudes during cutting (Siriphanich, 1993); it was among the first fresh-cut fruits to be sold in Thailand.

We describe here our survey conducted in 1996-97 of fresh-cut fruits sold in open-air markets vs. supermarkets for their quality and microbial populations.

In supermarkets, whole fruits that approach an unsalable condition are converted to freshcut products. They are processed under reasonably sanitary conditions (Fig. 1), placed on Styrofoam trays, wrapped with polyethylene film, and refrigerated at 5 to $10^{\circ} \mathrm{C}$ (Fig. 2). In open-air markets, good-quality ripe fruit are used for the fresh-cut products and are prepared on site throughout the day without special sanitary precautions (Figs. 3 and 4). Products are packaged in polyethylene bags that are partially or completely sealed and are displayed on tables at ambient temperature (30 to $35^{\circ} \mathrm{C}$ ) (Fig. 5). During the summer, some vendors place the packaged fruits on blocks of ice or cover them with crushed ice to lower their temperature. Most of the tables are shaded from direct sunlight.

\section{PREPARATION}

Fresh-cut fruits are prepared in various ways as follows:

Cantaloupe [Cucumis melo L. (Inodorus Group)] are cut into halves or smaller seg-

\footnotetext{
Received for publication 3 Mar. 1999. Accepted for publication 25 Aug. 1999. We thank Dr. Alley E. Watada and reviewers for critically reading this paper. This work was funded by the Chiang Mai Univ., Chiang Mai, Thailand. The cost of publishing this paper was defrayed in part by the payment of page charges. Under postal regulations, this paper therefore must be hereby marked advertisement solely to indicate this fact.
}

ments with seeds, and the skin is removed. Segments are cut in longitudinal or crosssections.

The husk of the durian contains many sharp spines, making removal difficult, so consumers prefer to purchase durian in the ready-toeat form. The husk can be removed from a fully ripe fruit more easily than from a partially ripe fruit; however, Thai consumers preferdurian at the partially ripe stage (Siriphanich, 1993). Fruit are dehusked and the edible pulp is packaged whole or as segments (Fig. 6).

Green and partially ripe mangos (Mangifera indica L.) are peeled and cut into pieces or sliced longitudinally (Fig. 7). A small package of heavy syrup from palm or cane sugar mixed with salt and chili is included in the package for seasoning.

Guava (Psidium guajava L.) fruits are usually cut in half or into smaller segments and the seeds are typically removed. Some fruits, particularly those with blemished skin, are peeled. A packet of seasoning may be included in the package.

Jackfruit generally are sold as a fresh-cut product only in open-air markets. They are either cut in half longitudinally or in crosssections with the core removed. Longitudinal

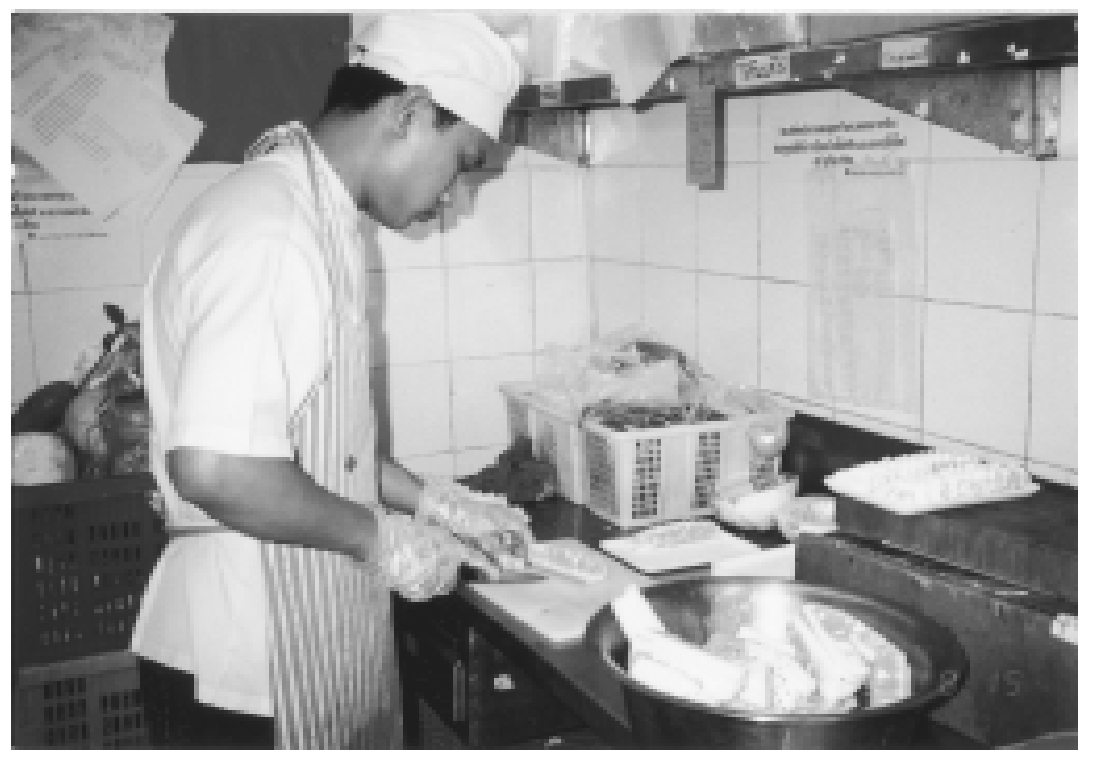

Fig. 1. Preparation of fresh-cut fruit in a supermarket in Thailand.

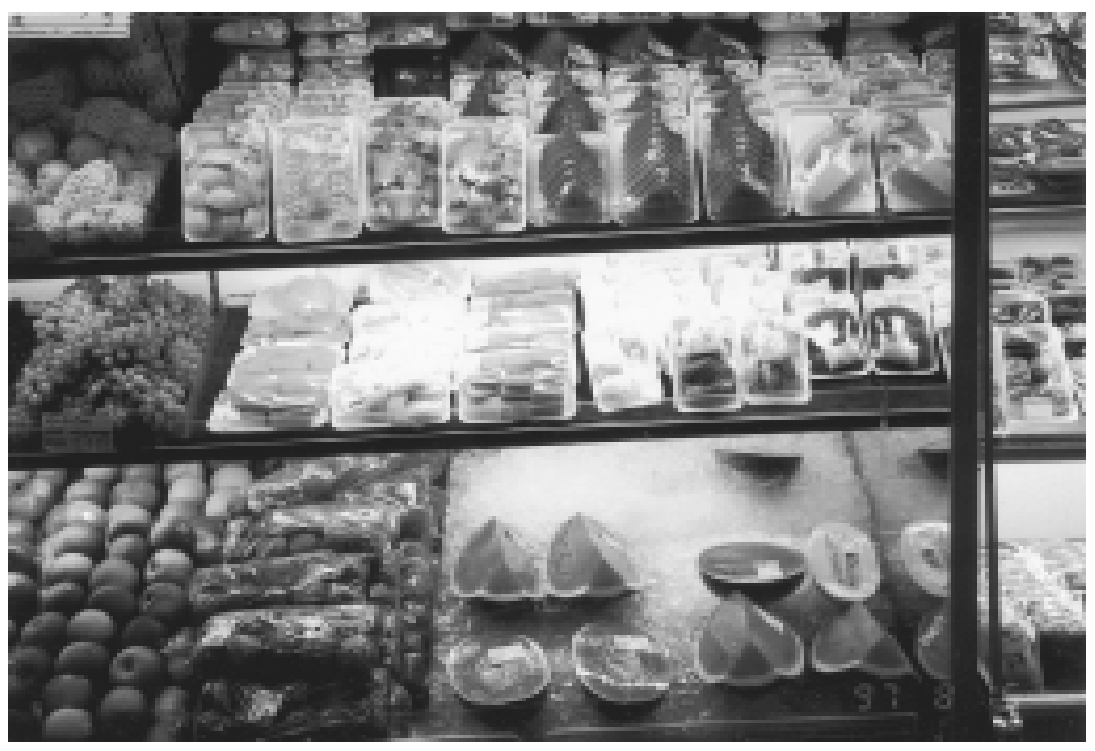

Fig. 2. Display of fresh-cut fruit in a supermarket in Thailand. Note the use of plastic wrap and foam trays. 
cutting is preferred by the retailers in Chiang Mai. Preparation of jackfruit is difficult and time-consuming because the latex exudes during cutting. To minimize the problem, hands and knives are coated with margarine or cooking oil, and the latex is removed from the fruit with paper or plastic sheets. After the core is removed, the fruitlets and surrounding tissues are separated and the fruitlet is cut off from the skin. The single seed is then removed from the fruitlet by cutting longitudinally. Most freshcut jackfruit are prepared by vendors. Jackfruit fruitlets are displayed in bulk, or on blocks of ice during the summer, and packaged only as needed by the consumer. In 1998 , the cost of fresh-cut jackfruit ranged from 80 to 160 Baht (U.S. \$2-4) per kilogram, depending on season and availability.

Papaya fruits are peeled, cut longitudinally in halves, quarters, or cross-sectioned, and the seeds are removed (Fig. 3).

Pineapple fruits are peeled, cored, and sold as whole fruit, or are cut into halves, quarters, or longitudinal slices or cross-sections (Figs. 4 and 5). In supermarkets, a small bag of sugar, salt, and chili may be included in the package for seasoning the pineapple slices.

Pummelo (Citrus maxima L.) fruits are peeled (see front cover of this issue, top) and whole or half fruit are wrapped with plastic film (shrink wrap). In supermarkets, segments of peeled pummelo may be separated and the membranes removed. Seasoning may be included in the package with four or five segments.

Roseapple [Syzgiium jambos (L.)] fruits are cut longitudinally into halves, and inedible parts and seeds are removed before packaging.

Watermelon may be sold in halves, quarters, or small segments or sliced into cross-sections. At the supermarket, the small segments may have the rind attached (Figs. 2 and 5).

Young coconut (Cocos nucifera L.) fruits are processed by wholesalers. The outer shell is peeled off with a sharp knife and the remainder left in a cone-shaped form (Fig. 8). Browning is inhibited by soaking the peeled fruit in sodium hydrosulfite solution for a few minutes. Treated coconuts are packed in plastic bags (10 fruit per bag) and sold to retailers, generally for the equivalent of U.S. \$2-3 per bag (1998 price).

Mixed fruits are sold only in supermarkets. Generally, two to four types of fresh-cut fruit, like pineapple, papaya, melons, and roseapple, are packaged together. One may find imported fruits, such as apple, grape, and pear, added to the package. The combination of fruit within a package depends upon seasonal availability.

\section{QUALITY OF FRUIT FROM OPEN- AIR VS. SUPERMARKETS}

The sensory quality of these fresh-cut fruits, as well as their freedom from microbes, can be highly variable because of variation in initial fruit quality, method of handling, and temperature; the latter varies between the supermarkets and open-air markets. We determined the microbial load and chemical composition of six fresh-cut fruits purchased at three differ-

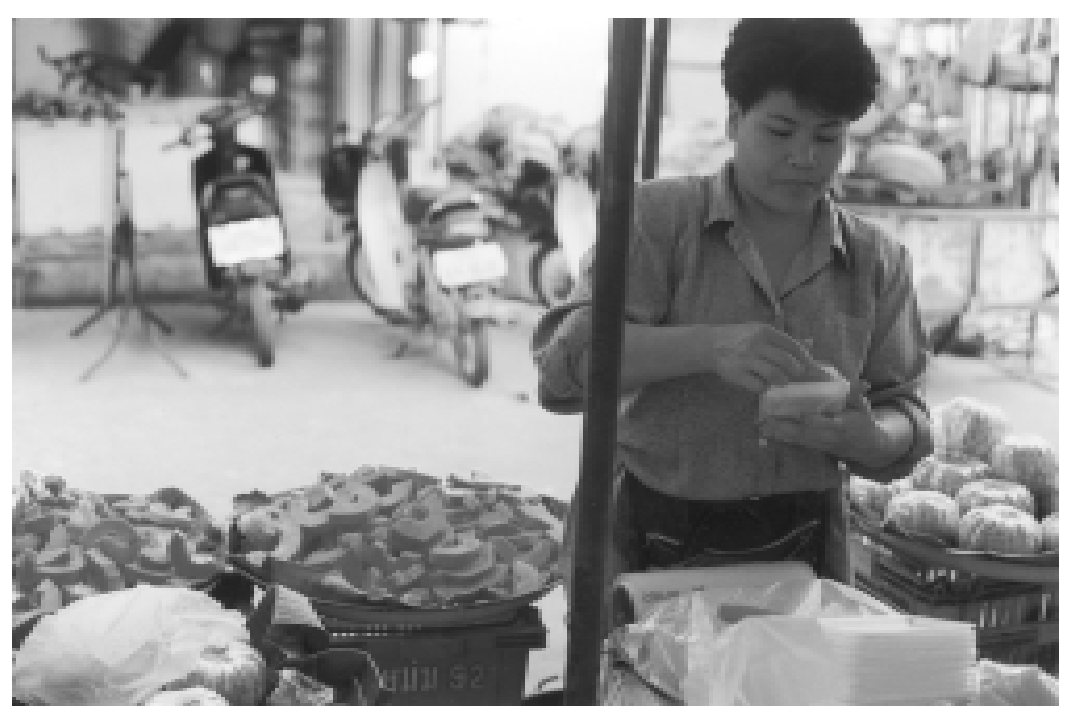

Fig. 3. Preparation of fresh-cut papaya in an open-air market in Thailand.

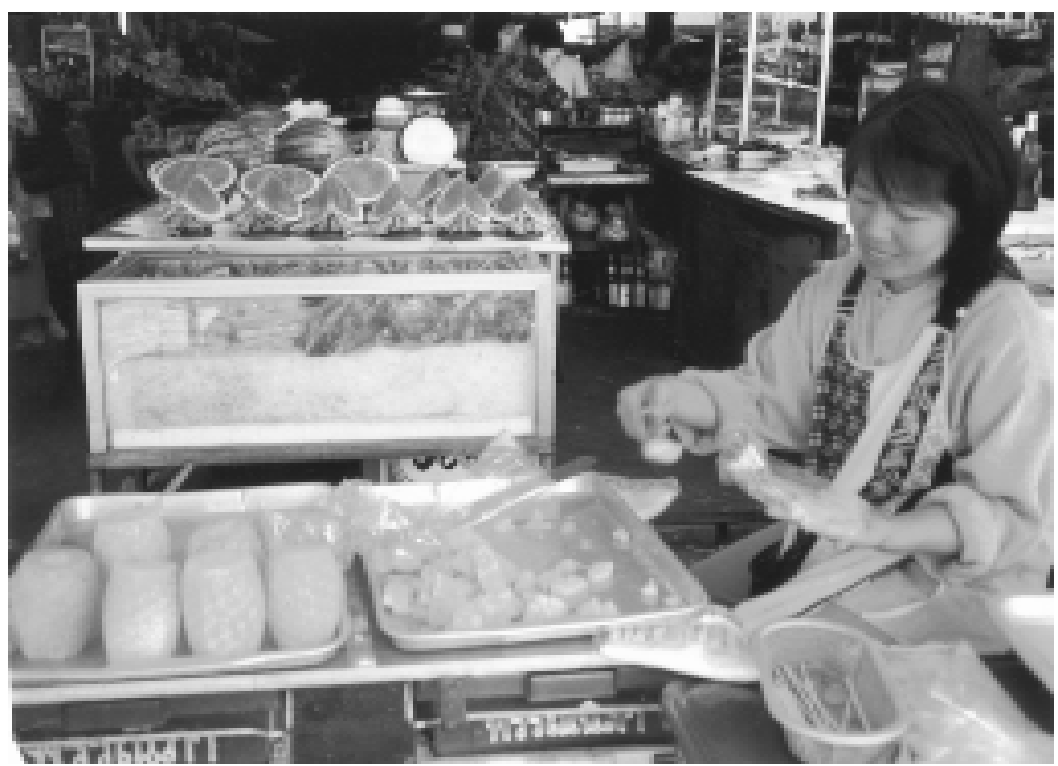

Fig. 4. Preparation of fresh-cut pineapple in an open-air market in Thailand. The fruit is displayed on crushed ice.

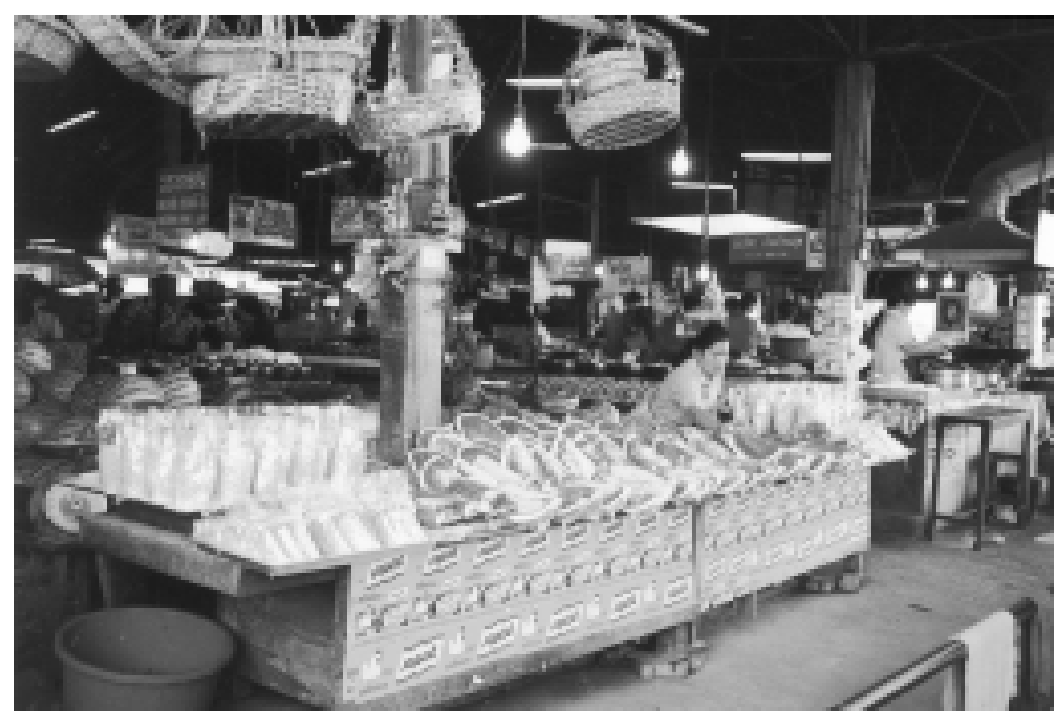

Fig. 5. Display of fresh-cut fruit in an open-air market in Thailand. 


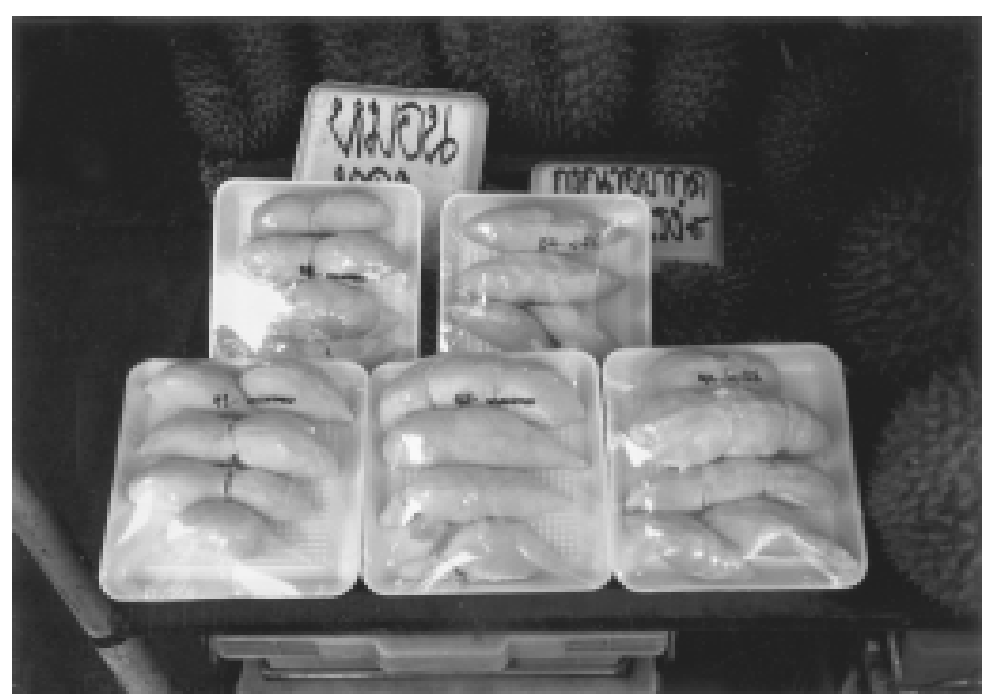

Fig. 6. Fresh-cut durian in an open-air market in Thailand.

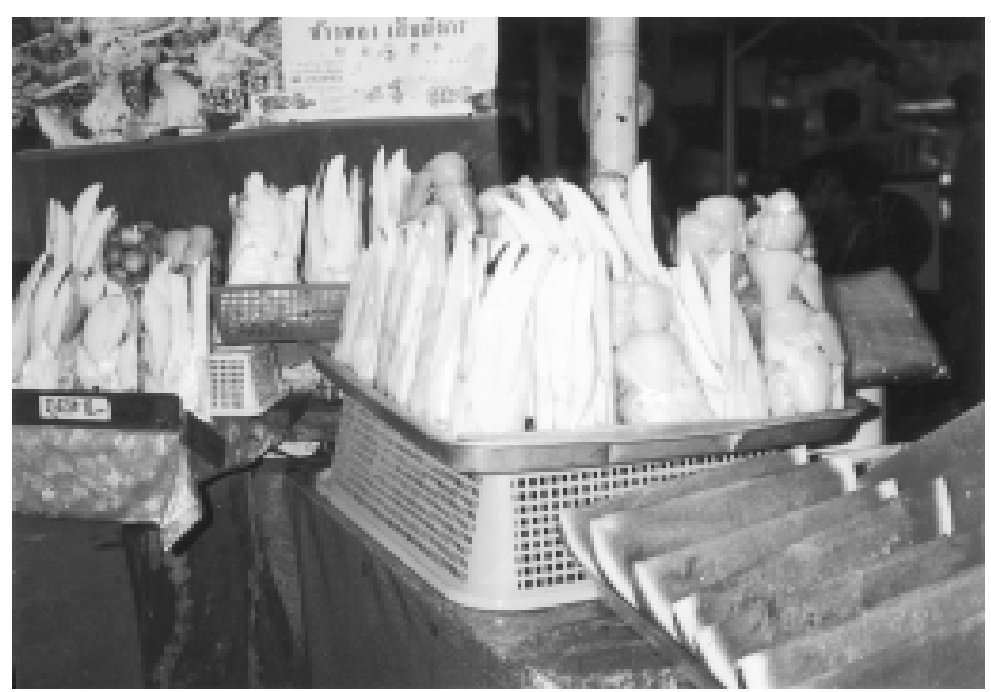

Fig. 7. Fresh-cut green mango in plastic bags in an open-air market in Thailand.

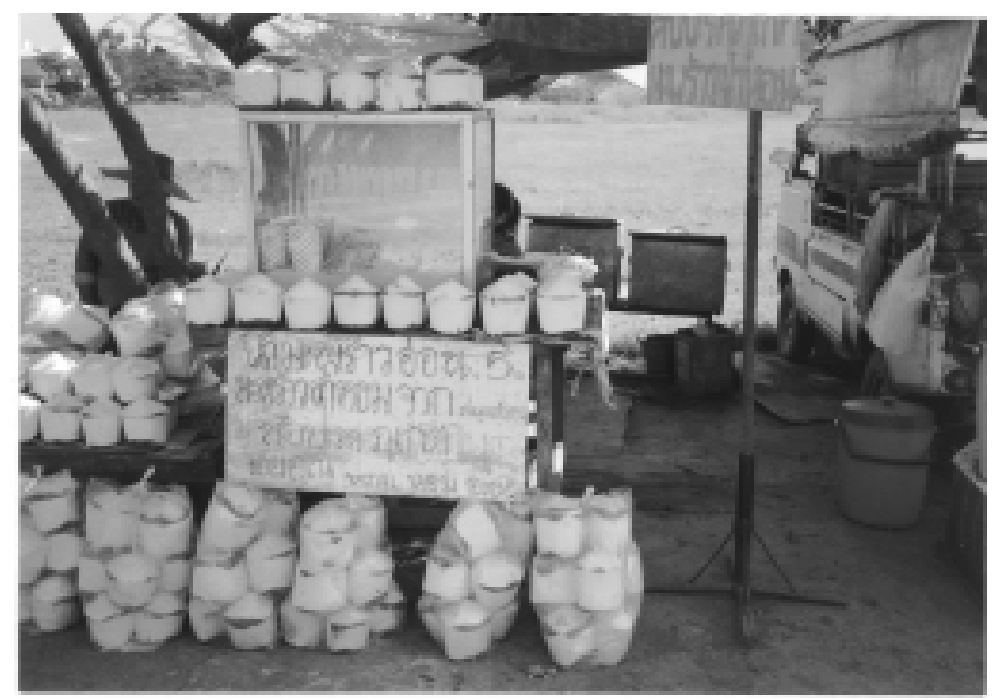

Fig. 8. Young coconut fruits in an open-air market in Thailand. The juice and soft flesh are consumed.. ent periods from four supermarkets or three open-air markets in Chiang Mai City over a 15-month period. The fruits surveyed included guava, cantaloupe, papaya, pineapple, pummelo, and watermelon. Only supermarket pummelo were analyzed because those at the open-air market were peeled, but not segmented as they were in the supermarket.

Microbial load was determined immediately after purchase. Composite samples (50 g) containing almost equal amounts from five packages were macerated with a blender (Stomacher Lab Blender Model 400, London) with $200 \mathrm{~mL}$ sterilized $0.1 \%$ peptone and $0.5 \% \mathrm{NaCl}$ solution for $1 \mathrm{~min}$. Subsequently, 10 -fold to 1000 -fold dilutions were prepared. Total plate counts and enterobacteria counts were made by the pore plate method using 1 $\mathrm{mL}$ of inoculum. The medium and incubation conditions for both counts were as described by O'Conner-Shaw et al. (1994).

Chemical analyses included dry matter, $\mathrm{pH}$, titratable acidity, total soluble solids, and ascorbic acid (vitamin C). Samples from five packages were homogenized and the juice separated from the pulp by using a Multipress compact (Braun 75, Kronberg, Germany). Titratable acidity was estimated by titrating an aliquot of blended juice with $0.1 \mathrm{~N} \mathrm{NaOH}$. Total soluble solids were determined with a hand refractometer (Atago N1, Tokyo); ascorbic acid (vitamin C) was determined by titration with 2,6-dichlorophenol-indophenol (Association of Official Analytical Chemists, 1990). A Warner Bratzler Meat Shear compression type (2830-013) was used to cut the tissue into $2 \times 2 \times 1 \mathrm{~cm}$ pieces (three pieces/ replication) on which shear force was determined at full scale of $100 \mathrm{~N}$ and cross-head speed of $200 \mathrm{~mm} \cdot \mathrm{min}^{-1}$ (Instron Model 5565, Universal Testing Machine, Instron Corp., Canton, Mass.) The microbial populations varied widely among sources and sampling times (Table 1). The maximum total microbial counts were substantially higher in guava and watermelon from the open-air market than in those from the supermarket; the reverse was true for cantaloupe and pineapple. The maximum populations of enterobacteria were substantially higher in guava and watermelon from the open market and cantaloupe from the supermarket than in other samples. One would expect the microbial population of fresh-cut fruits from the open-air market to be higher than those from supermarket because the latter are prepared in an enclosed area, where sanitation can be better controlled. This probably contributed to the very low total and enterobacteria populations on prepared guava products from the supermarket in comparison with those from the open-air market; however, similar differences were not noted with the other fruits. In fact, total plate counts were higher in some cases for supermarket than for open-air market products; this may have resulted from cross-contamination from Styrofoam trays during preparation. Microbial populations could also have varied with time between preparation and purchase of the fruit for analysis.

The average amount of ascorbic acid content in guava was not significantly different 


\section{Feature}

Table 1. Microbial population (range), average shear force, total soluble solids content, acidity, pH, and ascorbic acid contents of fresh-cut fruit purchased at openair markets vs. supermarkets in Chiang Mai, Thailand.

\begin{tabular}{|c|c|c|c|c|c|c|c|c|}
\hline \multirow[b]{2}{*}{ Fruit } & \multirow{2}{*}{$\begin{array}{l}\text { Source } \\
\text { (market) }\end{array}$} & \multicolumn{2}{|c|}{$\begin{array}{l}\text { Microbial counts } \\
\left(\times 10^{3} \mathrm{cfu}^{\mathrm{y}} / \mathrm{g}\right)\end{array}$} & \multirow{2}{*}{$\begin{array}{l}\text { Shear force } \\
\qquad(\mathrm{N})^{\mathrm{x}}\end{array}$} & \multirow{2}{*}{$\begin{array}{c}\text { Total } \\
\text { soluble } \\
\text { solids }(\%)^{\mathrm{x}}\end{array}$} & \multirow{2}{*}{$\begin{array}{c}\text { Acidity } \\
(\% \text { citric acid })^{\mathrm{x}}\end{array}$} & \multirow[b]{2}{*}{$\mathrm{pH}^{\mathrm{x}}$} & \multirow{2}{*}{$\begin{array}{l}\text { Ascorbic acid } \\
\left(\mathrm{mg} \cdot \mathrm{kg}^{-1} \text { juice }\right)^{\mathrm{x}}\end{array}$} \\
\hline & & Total & $\overline{\text { Enterobacteria }}$ & & & & & \\
\hline \multirow[t]{2}{*}{ Cantaloupe } & Open & $0.9-140$ & $0.03-38$ & $5.1 \pm 0.6$ & $6.6 \pm 1.5$ & $0.13 \pm 0.04$ & $4.9 \pm 0.3$ & $6 \pm 4$ \\
\hline & Super & $1.8-490$ & $0.05-86$ & $4.8 \pm 1.2$ & $7.5 \pm 1.6$ & $0.14 \pm 0.02$ & $5.0 \pm 0.4$ & $8 \pm 4$ \\
\hline \multirow[t]{2}{*}{ Guava } & Open & $2.2-730$ & $0.73-230$ & $14.9 \pm 2.2$ & $7.0 \pm 1.0$ & $0.50 \pm 0.05$ & $6.3 \pm 0.5$ & $1290 \pm 410$ \\
\hline & Super & $0.1-2.8$ & $0.01-0.73$ & $15.7 \pm 0.8$ & $7.0 \pm 1.6$ & $0.50 \pm 0.07$ & $6.3 \pm 0.4$ & $1680 \pm 440$ \\
\hline \multirow[t]{2}{*}{ Papaya } & Open & $6.0-8.6$ & $0.07-1.7$ & $1.7 \pm 1.0$ & $9.3 \pm 1.1$ & $0.17 \pm 0.04$ & $6.0 \pm 0.3$ & $550 \pm 150$ \\
\hline & Super & $2.6-11$ & $0.08-0.75$ & $1.6 \pm 0.5$ & $9.4 \pm 0.3$ & $0.16 \pm 0.05$ & $6.0 \pm 0.2$ & $760 \pm 90$ \\
\hline \multirow[t]{2}{*}{ Pineapple } & Open & $21-690$ & $0.02-11.0$ & $23.9 \pm 4.3$ & $13.1 \pm 0.9$ & $0.9 \pm 0.1$ & $4.2 \pm 0.3$ & $143 \pm 17$ \\
\hline & Super & $1.1-1200$ & $0.01-10.0$ & $23.8 \pm 4.5$ & $14.0 \pm 0.8$ & $0.7 \pm 0.1$ & $4.6 \pm 0.4$ & $122 \pm 22$ \\
\hline Pummelo & Super & $0.3-30$ & $0.03-4.7$ & $6.6 \pm 2.8$ & $9.9 \pm 1.1$ & $1.3 \pm 0.2$ & $4.5 \pm 0.5$ & $652 \pm 153$ \\
\hline \multirow[t]{2}{*}{ Watermelon } & Open & $2.3-95$ & $0.33-9.3$ & $3.3 \pm 2.4$ & $7.7 \pm 0.5$ & $0.12 \pm 0.02$ & $6.3 \pm 0.3$ & $64 \pm 24$ \\
\hline & Super & $0.5-68$ & $0.02-2.6$ & $3.5 \pm 1.4$ & $8.1 \pm 0.7$ & $0.12 \pm 0.04$ & $6.3 \pm 0.5$ & $42 \pm 26$ \\
\hline
\end{tabular}

${ }^{2}$ Range of values.

$\mathrm{y}_{\mathrm{cfu}}=$ coliform unit

${ }^{\mathrm{x}}$ Average \pm standard deviation of samples from three open-air markets or four supermarkets, three subsamples per market.

between fruit from the supermarket $(168$ $\mathrm{mg} \cdot 100 \mathrm{~g}^{-1}$ juice) and those from the open-air market (129 mg.100 $\mathrm{g}^{-1}$ juice). Similarly, the shear force, total soluble solids, acidity, and $\mathrm{pH}$ of fruits was not affected by source, perhaps because the maturity and stage of ripening were similar.

\section{CONCLUSIONS}

Our survey indicates that Thai consumers will find the quality of fresh-cut fruits to be similar whether they shop at open-air markets or supermarkets. Fruit quality and microbial status may deteriorate slightly faster at the open-air market due to lack of refrigeration; but fruit is prepared as needed and unsold products are discarded at the end of the day. Fresh-cut fruits at the supermarket are refrigerated and may be kept 1 or $2 \mathrm{~d}$ before being sold or discarded. Since fresh-cut fruits generally are consumed on the day of purchase, consumers probably will find little difference in quality regardless of place of purchase.

\section{Literature Cited}

Association of Official Analytical Chemists. 1990. Official methods of analysis. 15th ed. Assn. Offic. Anal. Chemists, Washington, D.C.

O'Connor-Shaw, R.E., R. Robert, A.L. Ford, and S.M. Nottingham. 1994. Shelf life of minimally processed honeydew, kiwifruit, papaya, pineapple and cantaloupe. J. Food Sci. 59:1202-1206.

Siriphanich, J. 1993. Minimal processing of tropical fruits, p. 127-137. In: B.R. Champ, E. Highley, and G.I. Johnson (eds.). Postharvest handling of tropical fruits. Austral. Ctr. Intl. Agr. Res. (ACIAR) Proc. No. 50. 